\title{
Sand Grain Size and Organic Matter Concentration in the Intertidal Zones on the Southwest Coast of Taiwan
}

\author{
Yih-Tsong Ueng ${ }^{*}$, Feng-Jiau Lin ${ }^{2}$, Chun-Wen Tsao ${ }^{1}$, Han-Chang Chen ${ }^{1}$, Wu-Chanl Chang ${ }^{1}$ \\ ${ }^{1}$ Department of Environmental Engineering, Kun-Shan University, Taiwan \\ ${ }^{2}$ Tainan Hydraulics Laboratory, National Cheng Kung University, Taiwan \\ Email: *ytueng@gmail.com
}

How to cite this paper: Ueng, Y.-T., Lin, F.-J., Tsao, C.-W., Chen, H.-C. and Chang, W.-C. (2021) Sand Grain Size and Organic Matter Concentration in the Intertidal Zones on the Southwest Coast of Taiwan. Natural Resources, 12, 108-123. https://doi.org/10.4236/nr.2021.124009

Received: March 8, 2021

Accepted: April 25, 2021

Published: April 28, 2021

Copyright $\odot 2021$ by author(s) and Scientific Research Publishing Inc. This work is licensed under the Creative Commons Attribution International License (CC BY 4.0).

http://creativecommons.org/licenses/by/4.0/ (c) (i) Open Access

\begin{abstract}
From April 2013 to April 2014, the average $\mathrm{pH}$ and water temperature of the Taisi oyster cultivation area (TS, Yunlin County, Taiwan) were 8.05 (7.35 $8.45)$ and $24.7^{\circ} \mathrm{C}\left(13.7^{\circ} \mathrm{C}-32.8^{\circ} \mathrm{C}\right)(\mathrm{N}=8226)$ The average organic matter $(\mathrm{OM})$ concentration at sites TS-A and TS-B were $6.9 \% \pm 1.3 \%$ and $6.9 \% \pm$ $1.2 \%$, and the weight of drift sand was $40.3 \pm 19.1 \mathrm{~g} / \mathrm{d} / \mathrm{m}^{2}$ and $28.5 \pm 34.3$ $\mathrm{g} / \mathrm{d} / \mathrm{m}^{2}(\mathrm{~N}=27)$. Considerable sand drifting typically occurs during the southwest monsoon season in summer. The average OM concentration at five dunes from Zhuoshui estuary to Zengwun estuary was $23.9 \pm 4.5 \mathrm{~g} / \mathrm{kg}$. The percentage of sand grain weight of $0.15-0.25 \mathrm{~mm}$ and $0.25-0.60 \mathrm{~mm}$ was $82.5 \% \pm 14.2 \%$ and $10.5 \% \pm 12.0 \%$. In the spring and autumn of 2015 , the average $\mathrm{OM}$ concentration at the eight intertidal zones from Hanbao to Cigu was $49.8 \pm 34.1 \mathrm{~g} / \mathrm{kg}(\mathrm{N}=177)$, and the OM concentrations at Huwei estuary and Hanbao and Fangyuan intertidal zones were relatively high. The OM concentration $(95.3 \pm 75.7 \mathrm{~g} / \mathrm{kg})$ of the low tide zone of Huwei estuary was the highest among all tidal zones. The OM concentration during spring (59.4 $\pm 41.7 \mathrm{~g} / \mathrm{kg}, \mathrm{N}=95)$ was higher than that in autumn $(39.1 \pm 17.8 \mathrm{~g} / \mathrm{kg}, \mathrm{N}=$ 84). For sand grain size ranges $0.15-0.25$ and $0.063-0.15 \mathrm{~mm}$, the weight ratio of intertidal sediment was $39.4 \% \pm 26.9 \%$ and $27.6 \% \pm 20.1 \%$, respectively. The broad and flat intertidal zone was marked by fine sand and long intertidal zone; the weight ratio of SGSs $<0.25 \mathrm{~mm}$ exceeded $65 \%$, and the OM concentration was between 20 and $30 \mathrm{~g} / \mathrm{kg}$. Coastal habitat diversity creates differences in biological communities, especially among crabs and benthic organisms. A greater understanding of coastal environments can aid in the management of coastal wetlands.
\end{abstract}

\section{Keywords}

Drift Sand, Intertidal Zone, Organic Matter, Sand Grain Size, Food Chain 


\section{Introduction}

The sandy intertidal zone on the west coast of Taiwan is an important wetland [1] [2] that is a habitat for shellfish such as oysters (Ostreidae: Crassostrea angulata), clams (Veneridae: Cyclina sinensis and Meretrix lusoria), square maca clams (Mactridae: Mactra veneriformis), and ribbed nassa (Nassariidae: Nassarius nodifer). The area is also a habitat for crabs: Mictyris brevidactylus (Mictyridae); Scylla serrata (Portunidae); Helice formosensis, Perisesarma bidens, and Nanosesarma minutum (Grapsidae) [3], and Ocypodidae crabs (Ilyoplax, Macrophthalmus, Ocypode, and Uca) [4]. Additionally, some species are in abundance in the zone but are less common in other areas, such as Phascolosoma arcuatum (Phascolosomatidae) and Laternula truncata (Laternulidae). What are the food sources of crabs and benthic animals living here? What is their demand?

Coastal sand dunes are aeolian landforms that undergo rapid and dynamic changes. They are affected by environmental factors such as wind speed and direction, tides and waves, terrain shelter, sand invasion and siltation, and plant dispersal; such dunes form a complex ecosystem [5]. Last 10 years, studies have been conducted on planktonic algae, productivity, and carbon cycles on the southwest coast, estuaries, and mudflats of Taiwan [6] [7]. Most related reports have indicated that some types of organic matter (OM) in seawater may come from land sources; for example, some OM enters seawater through river water transport. However, the volume of rainfall in the dry season in winter is small, and thus the volume of river water being transported to coastal areas is limited; at this time, northerly winds prevail, waves roll up the OM deposited on the seabed, and jetties obstruct sea currents, causing erosion. The remaining sand accumulates in coastal dunes, these may be a major source of $\mathrm{OM}$ in winter and spring.

$\mathrm{Xi}$ et al. (2015) reported that the proportions of fixed, semifixed, and mobile sand dunes in the Minqin desert area of Gansu Province, People's Republic of China, vary greatly and that soil nutrient content decreased with an increase in soil particles [8]. Liu et al. (2020) further indicated that when sediment (sand) in artificially fixed dunes became finer, the nutrient content of such dunes gradually increased; furthermore, researchers have stated that soil nutrients are substantially affected by sand grain size (SGS) [9]. OM and calcium carbonate concentrations in aeolian sandy soil in the Hulunbuir Sandy Land in Inner Mongolia were reported to be 31.1 and $2.7 \mathrm{~g} / \mathrm{kg}$, respectively; these concentrations have been used as a reference in other studies [10]. But the research on the coast of Taiwan is quite lacking.

The main crabs that inhabit the sand dunes on the west coast of Taiwan are Ocypode ceratophthalmus and $O$. sinensis. These crabs come out from their burrows for food at low tide. When the temperature on the beach increases, they return to their burrows. The depth of a burrow often reaches the water level in low tide areas; crabs dig and inhabit such deep burrows to ensure that their gills 
can be kept moist. $O$. sinensis crabs inhabit grasslands in the supralittoral zone. They use saddle vines and littorium for shade, and they can feed on hot days. These crabs are often observed eating debris on mudflats, beaches, and dunes.

The holotype of Chion ticaonicus Hanley, 1845 (Donacidae) was collected from the coastal area of Tainan, Taiwan, also found in this study. As the tide ebbs, this species filters its food in the flat intertidal zone. Assiminea latericea, Batillaria zonalis, and Cerithidea cingulate snails crawl and pursue prey mudflats. When mullets enter the tidal channel of shallow waters to chase prey at high tide. The Black-faced spoonbills and Great egrets also pursue prey them. At the same time, the Saunders's gull (Larus saundersi) also feed on abundant resources such as crab larvae and sentinel crabs. Coastal intertidal zone and estuary are affected by daily tides. The abundances of planktonic algae and the organic debris of algae remain unknown. Therefore, the comprehensive OM concentrations and the food sources of crabs and benthic.

\section{Materials and Methods}

\subsection{Oyster Cultivation Area}

\subsubsection{Sediment Monitoring}

From September 13, 2012, to September 28, 2013, we established a sampling site, TS-A, outside the Old Huwei estuary of the coastal oyster cultivation area at Taisi Township, Yunlin County, Taiwan. The southern side of the area is far from the sand dumping area. The sampling site TS-B was established outside the west seawall, which is located near the west side of Xinxing District [11] (Figure 1 and Figure 2).

On the suggestion of Dr. Jaw-Guei Lin from National Taiwan Ocean University, two glass bottles were hung on the bamboo poles of an oyster rack at the two sampling areas. The glass bottles had a length and diameter of 18.2 and 12.4 $\mathrm{cm}$, respectively, and the diameter at the bottle mouth was $8.7 \mathrm{~cm}$ (the cross-sectional area of the mouth was $120.76 \mathrm{~cm}^{2}$ ). To imitate the water depth at the oyster larval collection area, each glass bottle was positioned below the lowest tide. After hanging up the collected glass bottles, bring these bottles to the laboratory every 14 days and hang up new collection bottles, but for the first time the operation is carried out 16 days later (Figure 3).

After the samples were brought to the laboratory, they were dried in a precision oven (FuDaTaSoD-54) at $80^{\circ} \mathrm{C}$ for $12 \mathrm{~h}$, then stir and loosen the semi-dry sand and for another $12 \mathrm{~h}$. Then, the weight of dried sand was measured using a precision balance scale (SI-234) $\left(\mathrm{W}_{80^{\circ} \mathrm{C}}, \mathrm{g}\right)$, and the average daily volume of bleached sand was calculated $\left(\mathrm{g} / \mathrm{d} / \mathrm{m}^{2}\right)$. A high-temperature furnace $(\mathrm{FuDaTa} /$ FD-404) was then used to measure the OM concentration through dry ashing; the sample was heated in a high-temperature furnace $\left(800^{\circ} \mathrm{C}\right)$, and the $\mathrm{OM}$ concentration in the bleached sand was calculated after weighing $\left(\mathrm{W}_{800^{\circ} \mathrm{C}}, \mathrm{g}\right)$. Because when the oven temperature was to exceed $800^{\circ} \mathrm{C}, \mathrm{CaO}$ (lime) and $\mathrm{CO}_{2}$ would be easily generated because of the $\mathrm{CaCO}_{3}$ in shell debris. The OM concentration calculation formula was: $\mathrm{OM}(\%)=\left(\mathrm{W}_{80^{\circ} \mathrm{C}}-\mathrm{W}_{800^{\circ} \mathrm{C}}\right) / \mathrm{W}_{80^{\circ} \mathrm{C}} \times 100$ 


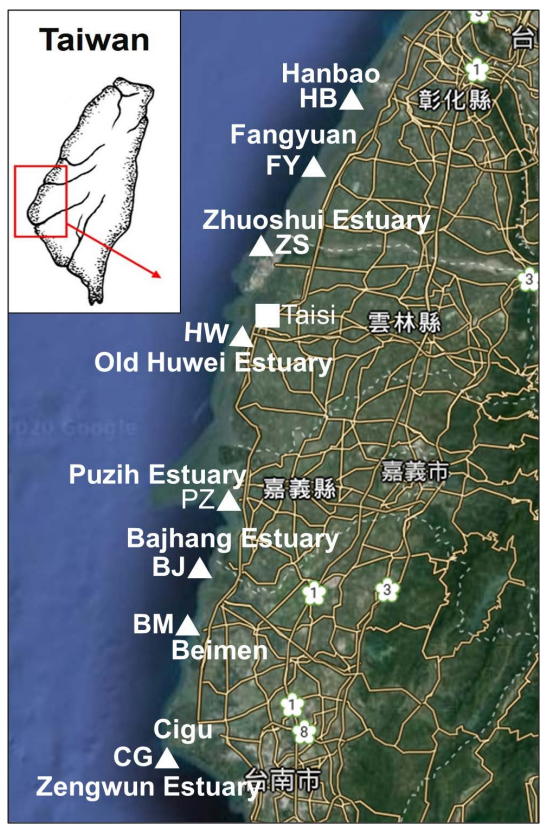

Figure 1. Sampling sites on the southwest coast of Taiwan (base map: Google, 2020 [12]).
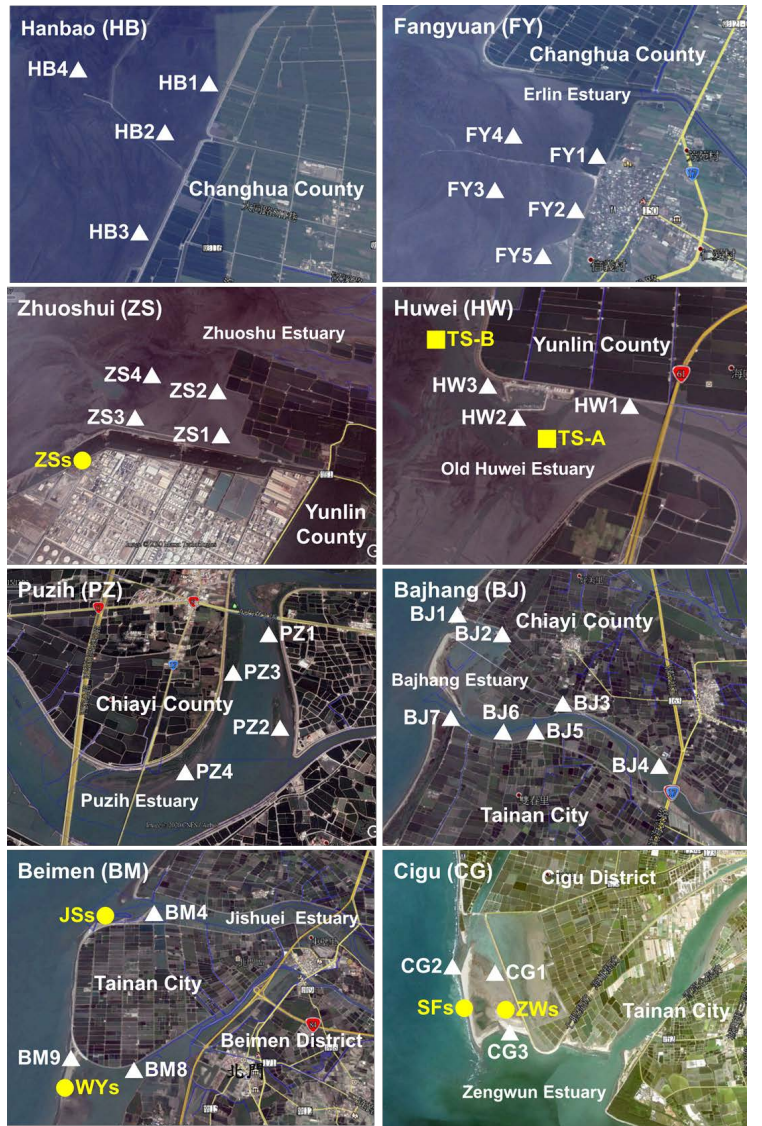

Figure 2. Schematic of the distribution of sampling sites and points along the southwest coast of Taiwan. The yellow squares represent oyster cultivation areas containing drifting sand, the yellow circles denote sand dunes, and the white triangles indicate intertidal zones (base map: Google, 2020 [12]). 


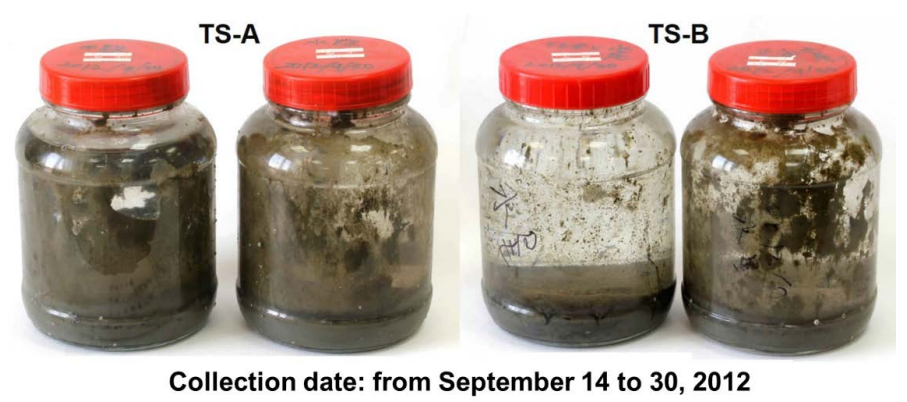

Figure 3. Drifted sand samples from the oyster cultivation area at Taisi, Yunlin County.

\subsubsection{Seawater Temperature and $\mathrm{pH}$ Monitoring}

From April 13, 2013, to April 15, 2014, seawater $\mathrm{pH}$ and temperature were monitored at the TS-A sampling site. Three $\mathrm{pH} 3310$ SET 2 monitors were hung on the bamboo poles of the oyster rack, and the hanging position was below the lowest tide level. The instruments were set to record the $\mathrm{pH}$ and temperature of seawater once every hour, and these instruments were collected and brought to the laboratory every 14 days to download data, perform maintenance, and replace by other new monitors.

\subsection{SGS Distribution and OM Concentration}

\subsubsection{Coastal Sand Dunes}

From January 28 to February 12, 2015 (the end of winter), sand dunes formed at Zhuoshui estuary (ZSs), Jishuei estuary (JSs), Wangyegang sandbar (WYs), Sinfulun sandbar (SFs), and Zengwun estuary (ZWs) (Figure 2). On each dune, four sampling points were located as follows: the front 1 ) windward edge; 2 ) windward slope; 3) sand dune top; and 4) leeward slope. At least $1 \mathrm{~kg}$ of sea sand was collected at each sample point over two seasons (total: 40 samples).

The research steps were as follows: 1) A shovel was used to remove the surface soil to a depth of $15 \mathrm{~cm}$. Subsequently, the collector further dug down $10 \mathrm{~cm}$ to collect samples. Each sample was collected in a plastic bag and brought to the laboratory for analysis; 2) Subsequently, $1 \mathrm{~kg}$ of sandy soil was placed in an $80^{\circ} \mathrm{C}$ oven and dried for $24 \mathrm{~h}$; 3) After removal from the oven, the clotted sand was crushed and then baked in an oven at $80^{\circ} \mathrm{C}$ for $4 \mathrm{~h}$ one more time, and measure dry (g); 4) Half of the sand was then removed and poured into an eight-layer

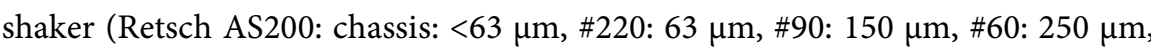
\#30: $600 \mu \mathrm{m}$, \#16: $1.18 \mathrm{~mm}$, \#8: $2.36 \mathrm{~mm}, \# 4:>4.75 \mathrm{~mm}$ ); 5) The sample was shaken in the shaker at $40 \mathrm{~Hz}$ for $10 \mathrm{~min}$. Then, the sand was removed from the various layers and weighed $(\mathrm{g})$ to determine its composition.

\subsubsection{Intertidal Zone}

From January 28 to October 26, 2015 (in spring and autumn), intertidal zone sampling was conducted at eight sampling sites. From north to south, they were as follows: Hanbao (HB1 to HB4) and Fangyuan (FY1 to FY5) of Changhua County; the Zhuoshui estuary (ZS1 to ZS4) and Old Huwei estuary (HW1 to 
HW3) of Yunlin County; the Puzih estuary (PZ1 to PZ4) of Chiayi County; and the Bajhang estuary (BJ1 to BJ7), Jishuei estuary (BM4), Beimen lagoon (BM8 and BM9), and Cigu District (CG1 to CG3) of Tainan (35 sampling points in total). Except for the sparse mangrove area at FY1, the sampling points were on beaches or mudflats (Figure 2).

In accordance with the Draft Coastal Situation Investigation and Operation Reference Manual composed by Hsu (2015), when sampling, the intertidal zone was divided into a high tide zone, low tide zone, and sublittoral zone, which reaches its lowest point before crossing approximately 1 meter deep. We had three sampling points in total and three replicates for each sampling point, for a total of 225 samples [4].

\subsubsection{Statistical Analysis}

Collected data are represented as the mean and standard deviation. The data were analyzed using subroutines in the statistical analysis programs SIMILARITY and CLUSTER (PRIMER v.6, PRIMER-E, Plymouth, UK) [13].

\section{Results}

\subsection{Seawater $\mathrm{pH}$ and Water Temperature in the Taisi Oyster Cultivation Area}

Over 358 days of monitoring (April 2013 to April 2014), in the TS oyster cultivation area, the average $\mathrm{pH}$ and water temperature were $8.05(7.35-8.45)$ and $24.7^{\circ} \mathrm{C}\left(13.7^{\circ} \mathrm{C}-32.8^{\circ} \mathrm{C}\right)$, respectively $(\mathrm{N}=8226)$ (Figure 4$)$. We obtained $\mathrm{pH}$ values lower than 7.5 on nine occasions; these low levels were caused by rainwater in upstream. In 201 records, the $\mathrm{pH}$ of general seawater was $\geq 8.3$. This could be from water pollution or similar reason of nearby industrial area.

\subsection{Drifted Sand and OM at the Taisi Oyster Cultivation Area}

The OM concentrations in sand collected from TS-A and TS-B were $6.9 \% \pm$ $1.4 \%$ and $6.9 \% \pm 1.2 \%$, respectively. The similarity of $\mathrm{OM}$ concentrations between the two sites TS-A and TS-B was $92.4 \%$. The average drifted sand weight per day at TS-A and TS-B were $40.3 \pm 19.1$ and $28.5 \pm 34 \mathrm{~g} / \mathrm{d} / \mathrm{m}^{2}$, respectively. The similarity of drifted sand weight between the two sites was $66.0 \%$. Abnormal amounts of drifted sand were mainly observed during the summer typhoon season (Figure 5).

In summer, the amount of drifted sand was affected by the southwest monsoon. The OM concentration was lower than $8 \%$ for the remainder of the sampling period, except from September 14 to 27, 2012, when it was 13.3\%. The amount of drifted sand captured of the range August 2 to 31, 2013 was between 137.6 and $147.9 \mathrm{~g} / \mathrm{d} / \mathrm{m}^{2}$ (Figure 5). Typhoons have an adverse financial impact on the oyster farming industry, and this is one of the main reasons fishers hang empty shells to collect oyster larvae and sell these oyster larvae in autumn. At the TS sites, when the amount of drifted sand was reduced, when waves were calm, or when winds were strong, the OM concentration was higher. However, during 
September 14 to 27, 2012, a high OM concentration was measured at TS-A; this was due to the accumulation of algal debris in the collection bottles (Figure 6).

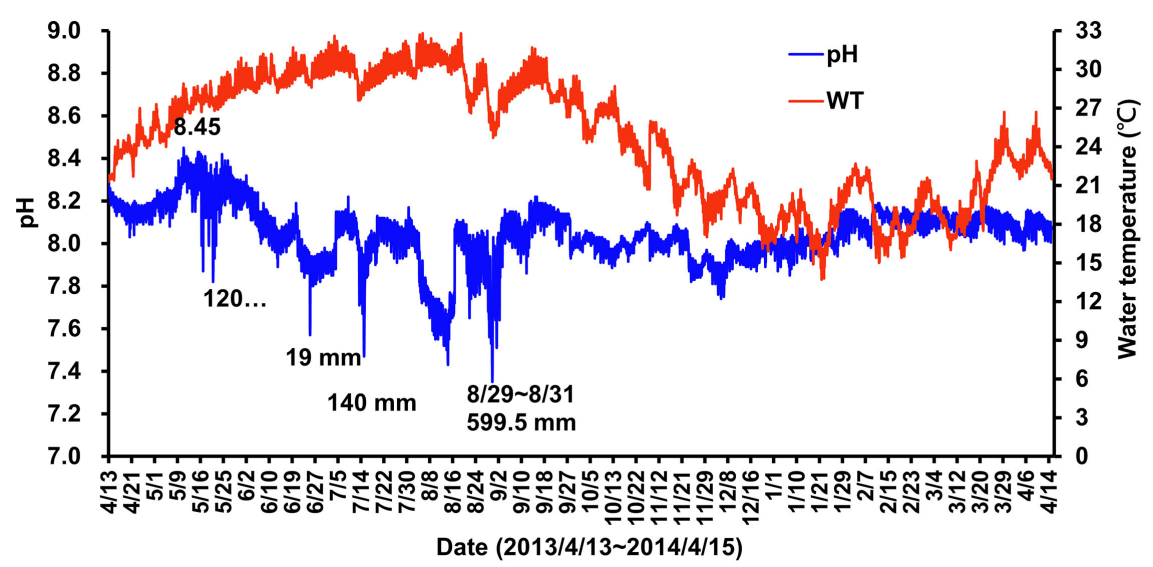

Figure 4. Changes in seawater $\mathrm{pH}$ and WT at the Taisi (TS) oyster cultivation area; precp: accumulated precipitation.

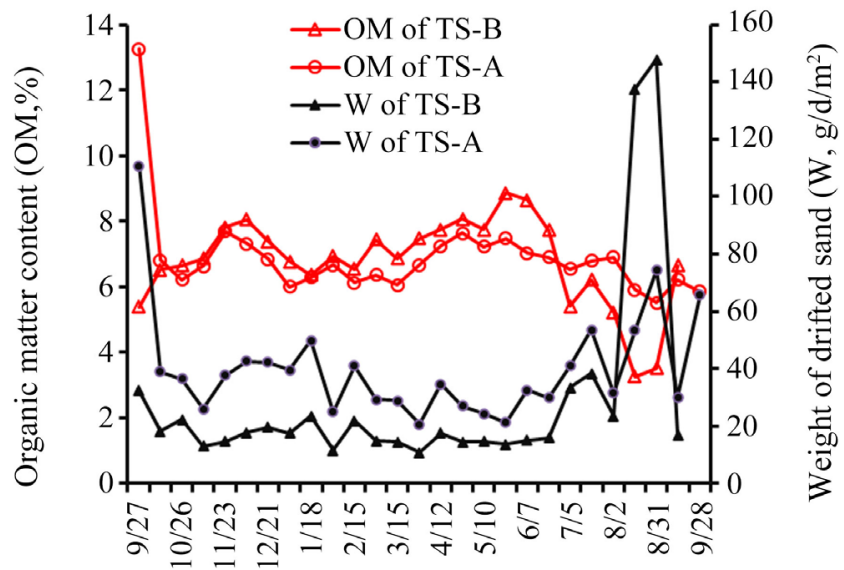

Date $(2012 / 9 / 14 \sim 2013 / 9 / 28)$

Figure 5. Changes in the OM concentration and amount of drifted sand at the Taisi (TS) oyster cultivation areas from September 2012 to September 2013.

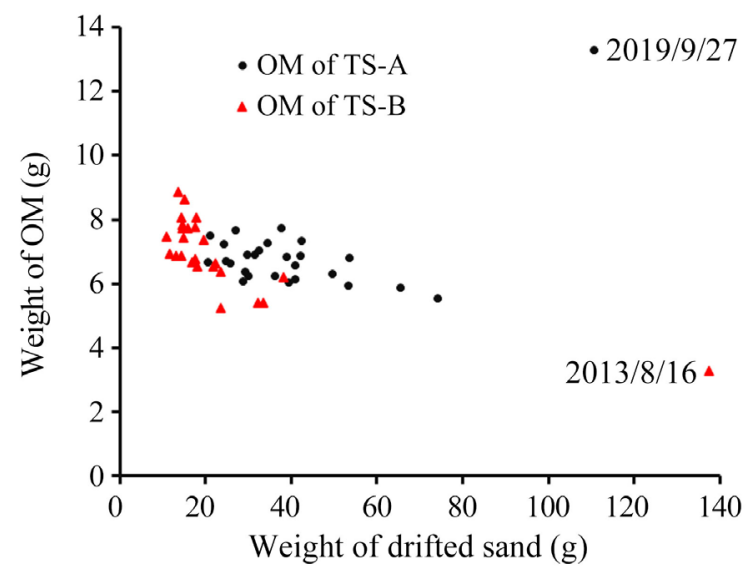

Figure 6. Relationship between the weight of drifted sand and OM concentration at the Taisi sites (TS-A and TS-B) from September 2012 to September 2013. 


\subsection{Coastal Sand Dunes}

\subsubsection{OM Concentration in Coastal Sand Dunes}

From January 28 to February 12, 2015 (the end of winter), at the five sample sites, the average OM concentration in the sand samples was $23.9 \pm 4.5 \mathrm{~g} / \mathrm{kg}$ (N $=40$ ). The OM concentrations at these five sampling sites (from north to south) were as follows: ZSs, $29.0 \pm 2.5 \mathrm{~g} / \mathrm{kg}$; JSs, $19.8 \pm 2.3 \mathrm{~g} / \mathrm{kg}$; WYs, $24.5 \pm 4.5 \mathrm{~g} / \mathrm{kg}$; SFs, $24.3 \pm 4.0 \mathrm{~g} / \mathrm{kg}$; and ZWs, $21.9 \pm 4.1 \mathrm{~g} / \mathrm{kg}(\mathrm{N}=8)$. The highest OM concentration was at ZSs, and the lowest was at JSs (Figure 7).

The average OM concentrations of samples taken at four sampling points related to wind direction (windward edge, windward slope, sand dune top, and leeward slope) were $23.7 \pm 4.2,23.1 \pm 4.6,26.7 \pm 5.5$, and $22.1 \pm 3.5 \mathrm{~g} / \mathrm{kg}$, respectively $(\mathrm{N}=10)$ (Figure 7$)$. Among the OM components at the five sites, the highest similarity was that between WYs and SFs (99.2\%) and the lowest was that between ZSs and JSs (81.1\%).

\subsubsection{SGS in Coastal Sand Dunes}

In dunes along the southwest coast of Taiwan, the weight percentage of SGS was mainly $0.15-0.25 \mathrm{~nm}(82.5 \% \pm 14.2 \%$, classified as fine sand), and $0.25-0.60$ $\mathrm{mm}(10.5 \% \pm 12.0 \%$, classified as medium sand). The similarity between the five plots was $69.0 \%-97.8 \%$, and less than $1.0 \%$ of sand was larger than $1.18 \mathrm{~mm}$ (classified as very coarse sand; Figure 8). Among the five sampling sites, the proportion of sand of size $0.25-0.60 \mathrm{~mm}$ was the highest in the ZSs dunes at approximately $31.6 \%$; at the other sampling areas, the proportion of sand in this size range was $2.81 \%-8.02 \%$ (Figure 8 ). The dissimilarity between the particle size distributions at ZSs and the other four plots was $31.3 \%$. The dissimilarity was $50.0 \%$ and $42.3 \%$, respectively, for the size ranges $0.15-0.25$ and $0.250-0.60$ mm (Figure 9).

\subsection{Intertidal Zone}

\subsubsection{OM Concentration in the Intertidal Zone}

From January to October 2015, the average concentration of OM in samples

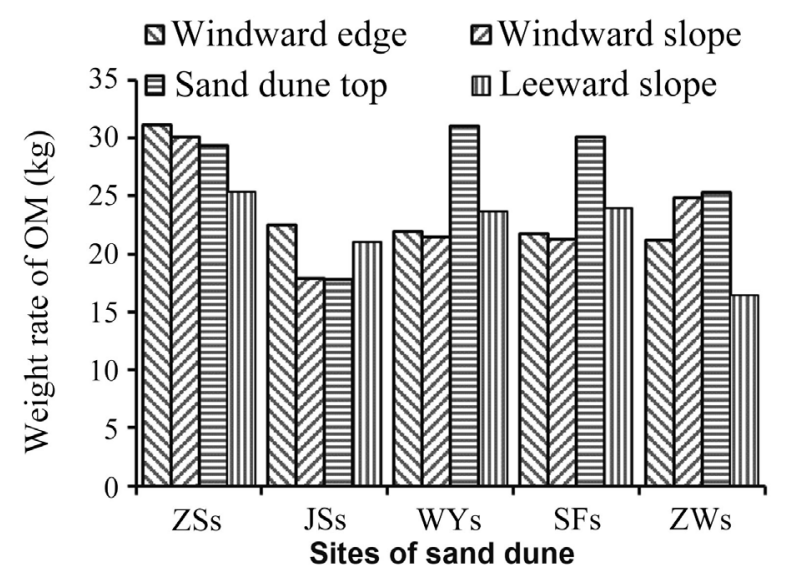

Figure 7. OM concentration $(\mathrm{g} / \mathrm{kg})$ and source composition of sand dunes along the southwest coast of Taiwan. 


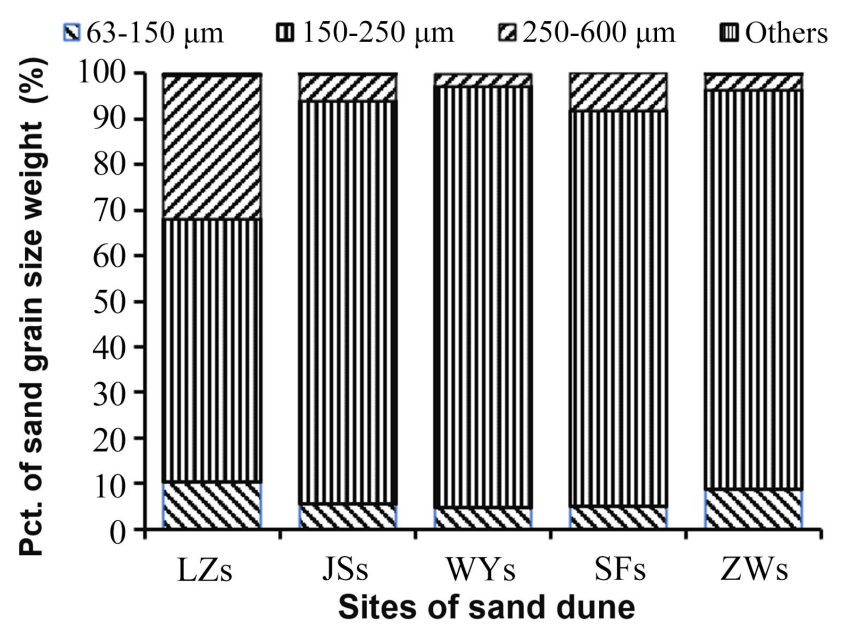

Figure 8. SGS composition (weight percentage, \%) of five sand dunes along the southwest coast of Taiwan.

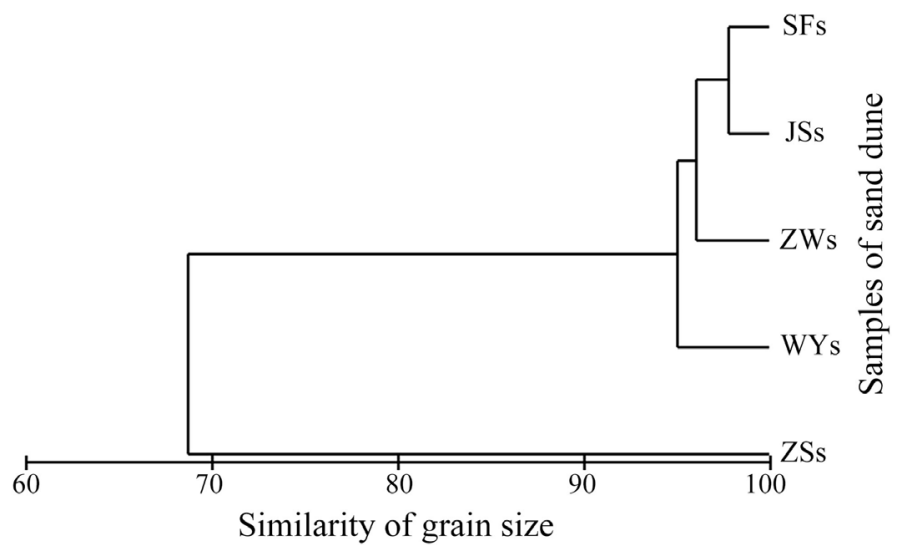

Figure 9. Similarity between SGSs weight percentage in different sand dunes along the southwest coast of Taiwan.

taken from the intertidal zone between Hanbao and Cigu (HB1 to HB4, FY1 to FY5, ZS1 to ZS4, HW1 to HW3, PZ1 to PZ4, BJ1 to BJ7, BM4, M8 and BM9, CG1 to CG3) was $47.3 \pm 31.1 \mathrm{~g} / \mathrm{kg}(\mathrm{N}=225)$. The average OM concentrations in samples taken from the eight aforementioned sites (from north to south) were as follows: $\mathrm{HB}, 71.2 \pm 47.6 \mathrm{~g} / \mathrm{kg}(\mathrm{N}=24) ; \mathrm{FY}, 63.2 \pm 28.9 \mathrm{~g} / \mathrm{kg}(\mathrm{N}=27) ; \mathrm{LZ}, 37.1 \pm$ $9.3 \mathrm{~g} / \mathrm{kg}(\mathrm{N}=24) ; \mathrm{HW}, 92.7 \pm 48.7 \mathrm{~g} / \mathrm{kg}(\mathrm{N}=6) ; \mathrm{PZ}, 26.2 \pm 14.4 \mathrm{~g} / \mathrm{kg}(\mathrm{N}=24) ;$ $\mathrm{BJ}, 45.4 \pm 31.9 \mathrm{~g} / \mathrm{kg}(\mathrm{N}=84) ; \mathrm{BM}, 40.0 \pm 29.6 \mathrm{~g} / \mathrm{kg}(\mathrm{N}=18) ;$ and CG, $47.7 \pm 26.7$ $\mathrm{g} / \mathrm{kg}(\mathrm{N}=18)$, respectively, Figure 10 . The OM concentration in spring (January and February), when little rainfall occurs, was $59.4 \pm 41.7 \mathrm{~g} / \mathrm{kg}(\mathrm{N}=95)$, and in autumn (September and October), after the typhoon season, it was $39.1 \pm 17.8$ $\mathrm{g} / \mathrm{kg}(\mathrm{N}=84)$.

At eight sampling sites and three tidal zones (high tide, low tide, and sublittoral zones), the samples with the highest OM concentration were those taken from the high tide zone at $\mathrm{HB}$ and FY ( 80.1 and $69.8 \mathrm{~g} / \mathrm{kg}$, respectively). In the low tide zone and sublittoral zone of HW, the highest OM concentration of 
samples was 95.3 and $82.6 \mathrm{~g} / \mathrm{kg}$, respectively. In the supralittoral zone at BM and CG, the OM concentration of samples was 70.1 and $68.3 \mathrm{~g} / \mathrm{kg}$, respectively (Figure 10). The OM concentration similarity between the low tide zone and sublittoral zone was $89.9 \%$, and the lowest similarity was that between the high tide zone and sublittoral zone (80.9\%). Furthermore, at the time of collection, all the soil samples at HB, FY, and HW were black and had a foul smell. These sampling sites did not contain benthic animals such as clams. The relative similarity between OM concentrations in the intertidal zones of the various sampling sites is presented in Figure 11.

\subsubsection{SGS in the Intertidal Zone}

In the three tidal zones (high tide zone, low tide zone, and sublittoral zone) of the eight sampling sites, for a SGS of $0.15-0.25 \mathrm{~mm}, 0.063-0.15 \mathrm{~mm}, 0.25-0.60$ $\mathrm{mm}$, and $<0.063 \mathrm{~mm}$, the percentage of sand grain weight. were $39.4 \% \pm 26.9 \%$, $27.6 \% \pm 20.1 \%, 18.7 \% \pm 15.3 \%$, and $10.7 \% \pm 11.2 \%$, respectively $(\mathrm{N}=216$; Figure 12).

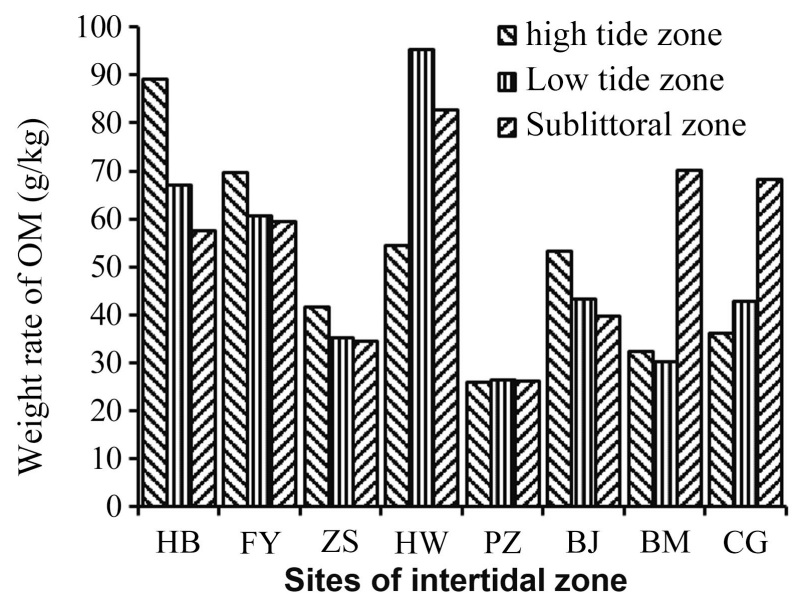

Figure 10. OM concentration at eight sample sites along the southwest coast of Taiwan.

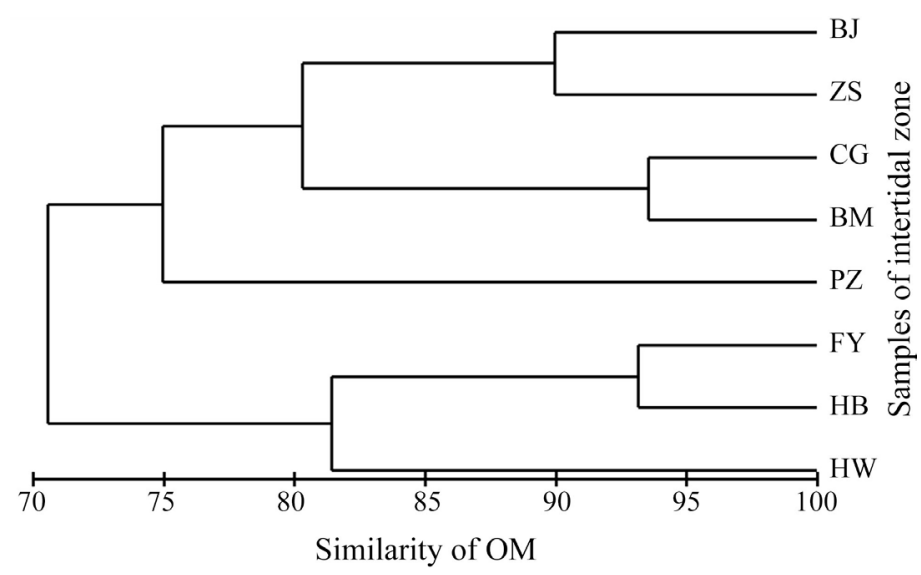

Figure 11. Similarity between OM concentrations in the intertidal zones of eight sampling sites. 


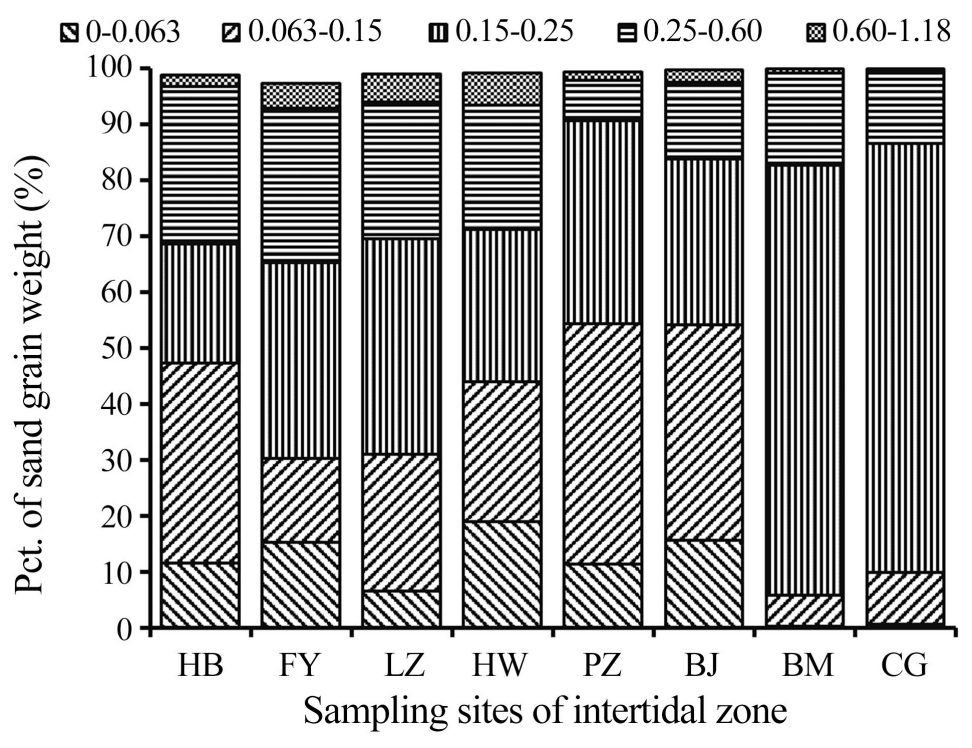

Figure 12. SGS composition by weight (\%) at eight sampling sites along the southwest coast of Taiwan.

\subsubsection{SGS in Different Seasons}

In spring (January and February), the percentage of sand grain weight of SGS ranges $0.15-0.25,0.063-0.15$, and $0.25-0.60 \mathrm{~mm}$ was $39.9 \% \pm 24.1 \%, 24.7 \% \pm$ $13.3 \%$, and $19.1 \% \pm 11.4 \%$, respectively; similarity within the spring samples was $55.2 \%$, and the contribution of rhese three ranges was $43.7 \%, 24.0 \%$, and $20.7 \%$, respectively (total: $88.4 \% ; \mathrm{N}=81$ ). In autumn (September and October), the percentage of sand grain weight of SGS ranges $0.15-0.25,0.063-0.15$, and 0.25 - $0.60 \mathrm{~mm}$ was $35.4 \% \pm 22.2 \%, 27.9 \% \pm 17.4 \%$, and $22.8 \% \pm 15.0 \%$, respectively; the similarity within the autumn sampling was $60.7 \%$, and the contribution of these three ranges was $36.5 \%, 28.7 \%$, and $24.3 \%$, respectively (total: $90.0 \% ; \mathrm{N}=$ 64). The dissimilarity of SGS between spring and autumn was $42.5 \%$, and the difference was mainly in the SGS ranges $0.15-0.25,0.063-0.15$, and $0.25-0.60$ $\mathrm{mm}$ was $34.5 \%, 26.1 \%$, and $18.7 \%$, respectively (total: $79.2 \%$ ).

\subsubsection{SGS at Different Tidal Zones}

In the sublittoral zone, for SGS ranges $0.15-0.25,0.25-0.60$, and $0.063-0.15$ $\mathrm{mm}$, the percentage of sand grain weight were $40.9 \% \pm 25.3 \%, 21.3 \% \pm 13.9 \%$, and $23.3 \% \pm 12.1 \%$, respectively (total: $56.9 \%$ ). The similarity within the ublittoral zone was $56.9 \%$, and the contribution of these three ranges was $44.5 \%$, $24.5 \%$, and $21.2 \%$, respectively (total: $90.2 \%)(\mathrm{N}=49)$.

In the low tide zone for SGS ranges $0.15-0.25,0.063-0.15$, and 0.25 to 0.60 $\mathrm{mm}$, the percentage of sand grain weight was $39.2 \% \pm 23.6 \%, 26.7 \% \pm 15.0 \%$, and $19.2 \% \pm 11.5 \%$, respectively. The similarity within the low tide zon was $55.7 \%$, and the contribution of these three ranges was $42.3 \%, 26.9 \%$, and $20.7 \%$, respectively (total: $89.9 \%)$. $(\mathrm{N}=51)$.

In the high tide zone, for SGS ranges $0.15-0.25,0.063-0.15$, and $0.25-0.60$ $\mathrm{mm}$, the percentage of sand grain weight was $38.6 \% \pm 23.7 \%, 26.0 \% \pm 15.8 \%$, 
and $21.0 \% \pm 12.8 \%$, respectively. The similarity within the high tide zone was $58.3 \%$, and the contribution of the first three ranges was $40.7 \%, 27.0 \%$, and $22.0 \%$, respectively (total: $89.7 \%)(\mathrm{N}=51)$.

The dissimilarity of SGS between the sublittoral zone and low tide zone was 43.3\%; the main SGS ranges that contributed to the dissimilarity were, in the following order, $0.15-0.25 \mathrm{~mm}$ (35.6\%), $0.063-0.15 \mathrm{~mm}$ (26.3\%), and 0.25 $0.60 \mathrm{~mm}(17.5 \%)$. These ranges and ratios explained $79.4 \%$ of the dissimilarity. The dissimilarity between the sublittoral zone and high tide zone was $42.0 \%$. The main SGS ranges that contributed to the dissimilarity were $0.15-0.25 \mathrm{~mm}$ (35.8\%), $0.063-0.15 \mathrm{~mm}$ (25.6\%), and $0.25-0.60 \mathrm{~mm}$ (18.3\%). These ranges and ratios explained $79.7 \%$ of the dissimilarity. The dissimilarity between the low tide zone and high tide zone was $42.6 \%$, and the main SGS ranges that contributed to this dissimilarity were $0.15-0.25 \mathrm{~mm}(35.3 \%), 0.063-0.15 \mathrm{~mm}$ (25.5\%) and $0.25-0.60 \mathrm{~mm}$ (18.6\%). These ranges and ratios explained $79.4 \%$ of the dissimilarity. The dissimilarity SGS between the sublittoral zone, low tide zone, and high tide zone was $40 \%-50 \%$.

\subsubsection{SGS at Each Tidal Zones Sampling Site}

The SGS distribution at different sampling sites is shown in Figure 13, and the similarity values are presented in Figure 14

At HB tidal zones, for SGS ranges $0.063-0.15,0.15-0.25$, and $0.25-0.60 \mathrm{~mm}$, the percentage of sand grain weight were $35.7 \% \pm 26.1 \%, 21.2 \% \pm 12.9 \%$, and $28.2 \% \pm 28.9 \%$, respectively (Figure 13 ). The similarity within $\mathrm{HB}$ site was $55.1 \%$, and the contribution of these three ranges was $37.3 \%, 25.5 \%$, and $23.1 \%$, respectively (total: $85.9 \%)(\mathrm{N}=23)$.

At FY tidal zones, for SGS ranges $0.15-0.25,0.25-0.60$, and $0.063-0.15 \mathrm{~mm}$, the percentage of sand grain weight were $34.9 \% \pm 22.7 \%, 21.7 \% \pm 21.5 \%$, and $15.0 \% \pm 10.7 \%$, respectively; the similarity within FY site was $64.8 \%$, and the contribution of these three ranges was $35.0 \%, 33.2 \%$, and $16.4 \%$, respectively (total: $84.6 \%)(\mathrm{N}=27)$.

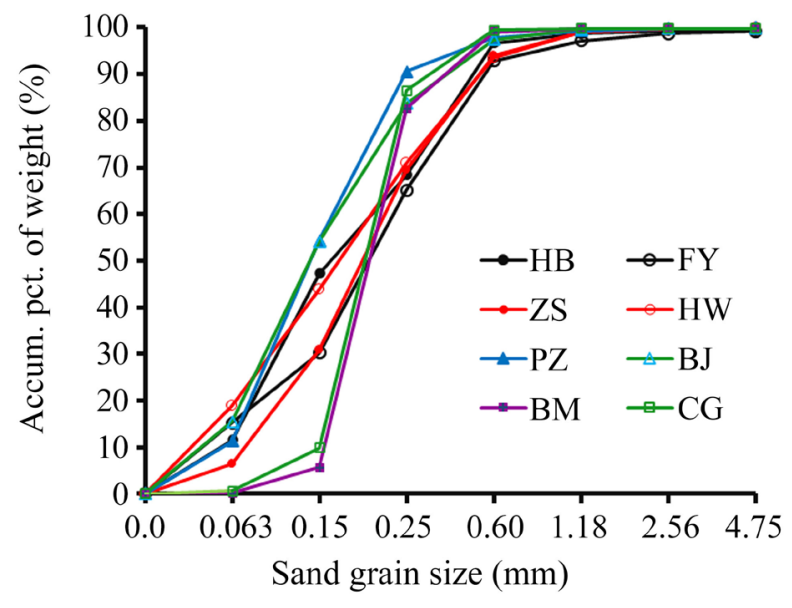

Figure 13. Accumulated percentage of sand grain weight in the intertidal zone along the southwest coast of Taiwan. 


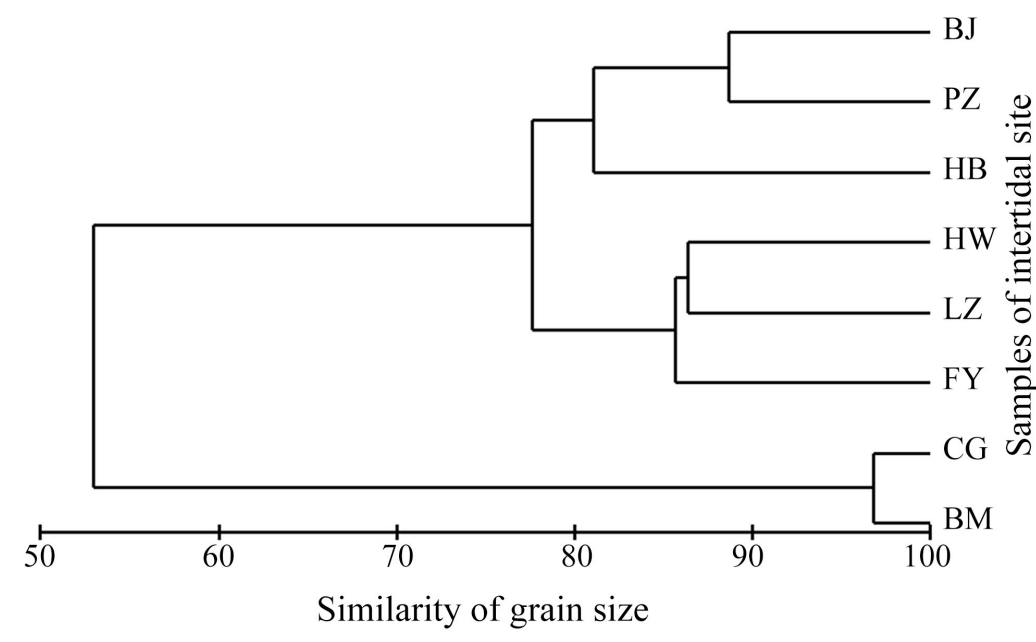

Figure 14. Similarity in SGS distribution in intertidal zones on the southwest coast of Taiwan.

At ZS tidal zones, for SGS ranges $0.15-0.25,0.25-0.60$, and $0.063-0.15 \mathrm{~mm}$, the percentage of sand grain weight were $38.4 \% \pm 28.6 \%, 24.5 \% \pm 16.7 \%$, and $24.5 \% \pm 16.5 \%$, respectively; the similarity within ZS site was $66.7 \%$, and the contribution of these three ranges was $42.9 \%, 25.1 \%$ and $24.8 \%$, respectively (total: $92.8 \%)(\mathrm{N}=24)$.

At HW tidal zones, for SGS ranges $0.063-0.15,0.15-0.25$, and $0.00-0.063$ $\mathrm{mm}$, the percentage of sand grain weight were $39.5 \% \pm 29.3 \%, 21.3 \% \pm 15.2 \%$, and $15.9 \% \pm 9.9 \%$, respectively. The similarity within HW site was $66.5 \%$, and the contribution of these three ranges was $30.0 \%, 25.6 \%$, and $22.5 \%$, respectively (total: 78.1\%) $(\mathrm{N}=6)$.

At PZ tidal zones, for SGS ranges $0.063-0.15,0.15-0.25$, and $0.00-0.063$ $\mathrm{mm}$, the percentage of sand grain weight were $43.0 \% \pm 16.1 \%, 36.2 \% \pm 25.6 \%$, and $11.4 \% \pm 9.3 \%$, respectively. The similarity within PZ site was $66.1 \%$, and the contribution of these three ranges was $50.9 \%, 32.3 \%$, and $9.1 \%$, respectively (total: $92.3 \%)(\mathrm{N}=24)$.

At BJ tidal zones, for SGS ranges $0.063-0.15,0.15-0.25$, and $0.00-0.063 \mathrm{~mm}$, the percentage of sand grain weight were $39.5 \% \pm 29.3 \%, 21.3 \% \pm 15.2 \%$, and $15.9 \% \pm 9.9 \%$, respectively; the similarity within $\mathrm{BJ}$ site was $65.4 \%$, and the contribution of these three ranges was $44.8 \%, 23.3 \%$ and $15.1 \%$, respectively (total: 83.2\%) $(\mathrm{N}=41)$.

At BM tidal zones, for SGS ranges $0.15-0.25$ and $0.25-0.63 \mathrm{~mm}$, the percentage of sand grain weight were $77.3 \% \pm 6.7 \%$ and $14.7 \% \pm 8.8 \%$, respectively; the similarity within $\mathrm{BM}$ site was $87.9 \%$, and the contribution of these two ranges was $83.6 \%$ and $10.9 \%$, respectively (total: $78.1 \%)(\mathrm{N}=12)$.

At CG tidal zones, for SGS ranges $0.15-0.25$ and $0.25-0.63 \mathrm{~mm}$, the percentage of sand grain weight were $76.7 \% \pm 7.7 \%$ and $12.9 \% \pm 6.4 \%$, respectively; the similarity within CG site was $87.7 \%$, and the contribution of these two ranges was $82.4 \%$ and $10.5 \%$, respectively (total: $92.9 \%)(\mathrm{N}=9)$. 


\section{Discussion}

In May 2013, the $\mathrm{pH}$ level measured at the oyster cultivation area (TS-A site) was $\geq 8.3$ (Figure 5), the average value of seawater $\mathrm{pH}$. This high level is difficult to explain; it may have been influenced by neighboring industrial areas. This level was also obtained by several monitoring units on the west coast of Taiwan (Yunlin), which discovered that $\mathrm{pH}$ rose between 2009 and 2010 [14]. Additionally, when the wind was low, waves were calm, and the amount of floating sand along the coast was small, the amount of OM passively captured (settling) through the mouth of the sampling bottles was higher. When the wind was high and waves were strong, although a considerable extent of grain occurred, the OM concentrations in samples were lower and the seawater had higher turbidity, which adversely affected the growth of oysters [15] [16].

The SGS in ZSs coastal dunes were relatively large, and this may have been related to sand transport from Zhuoshu River (Figure 8). The high OM concentration at ZSs was related to wastewater discharge from livestock husbandry, which sides on the north bank of the estuary (Figure 7).

The high OM concentration in the intertidal zone at HW was related to the surrounding fish farm and the area's coastal topology (Figure 10). The large SGSs at the BM and CG sites were due to coastal erosion. The intertidal zones at $\mathrm{HB}, \mathrm{FY}, \mathrm{ZS}$, and HW have long been affected by sand transportation from Zhuoshu estuary.

In the intertidal zone, the weight ratio of different SGSs in spring and autumn was the same, and the order was as follows: $0.15-0.25 \mathrm{~mm}>0.063-0.15 \mathrm{~mm}>$ $0.25-0.60 \mathrm{~mm}$. The SGS percentage of sand grain weight similarity was $42.5 \%$. The OM concentration in the intertidal zone in spring, when little rainfall occurs, was higher than that in autumn, after the typhoon season (59.4 vs 39.1 $\mathrm{g} / \mathrm{kg}$ ). This was an unexpected result. Perhaps the debris that washed into the estuary during the rainy season was more likely to be transported by the sea after winter, or perhaps the northerly wind in winter blew OM from the sand dunes into the sea.

The SGS distribution in different tidal zones was inconsistent; the dissimilarity in SGS between the three tidal zones was $40 \%$ - 43\%. First, the SGS at BM and CG, which undergo severe erosion due to their coastal locations, was in the following order: $0.15-0.25 \mathrm{~mm}>0.25-0.63 \mathrm{~mm}$; the weight ratio at $\mathrm{BM}$ was as high as $76 \%$. Second, the slightly silty sand at HB, PZ, and BJ (Figure 3 ) had a size range of $0.063-0.15 \mathrm{~mm}$. The broad and flat intertidal zone was marked by fine sand and long intertidal zone; the weight ratio of SGSs $<0.25 \mathrm{~mm}$ exceeded $65 \%$, and the OM concentration was between 20 and $30 \mathrm{~g} / \mathrm{kg}$ [16]. This OM concentration has provided crab and benthic habitats (for example Grapsidae, Mictyridae, Ocypodidae, and Veneridae) and increased biodiversity here, respectively.

\section{Acknowledgements}

We are grateful to Mr. Ya-Su Luo, Ms. Jun-Fang Chang, Mr. Shir-Zu Lin, Mr. 
Meng-Han Shie, Mr. Jie-Fu Tsai, Mr. Yu-An Lin, Mr. Po-Ling Deng, Mr. Geng-Yao Chang, and Mr. Jin-Lang Lin (a fisherman) for their assistance with fieldwork and data collection. This study was supported by the Industrial Development Bureau; the Construction and Planning Agency, the Ministry of the Interior; the Tainan City Government; Chiayi County Government; and the Wild Bird Society of Changhua.

\section{Conflicts of Interest}

The authors declare no conflicts of interest regarding the publication of this paper.

\section{References}

[1] Chang, C.-L. (1995) Geomorphological Study of Sand Dunes in Western Coast of Taiwan. Ph.D. Thesis, Department of Geography, Chinese Culture University, Taiwan, $84 \mathrm{p}$.

[2] Yang, J., Y.-C., Ueng, Y.-T. (2011) Taiwan's Wetlands of Importance. Urban and Rural Development Branch, Construction and Planning Agency, Ministry of the Interior, Taipei, $192 \mathrm{p}$.

[3] Chen, K.-N., Hsu, J.-T. Ueng, Y.-T. (2017) Population Structure and Fecundity of Two Species of Grapsid Crabs (Brachyura, Grapsidae) that Inhabit the Oyster Reefs of Western Taiwan. Crustaceana, 90, 1699-1714. https://doi.org/10.1163/15685403-00003734

[4] Hsu, J.-T. (2015) Standard Operating Procedures Manual for the Coastal Survey $(1 / 2)$ (The Case Study on Kaohsiung and Pingtung). Water Resources Planning Institute, Water Resources Agency, Ministry of Economic Affairs, 624 p.

[5] Chen, Y.-H., and Lee, C.-T. (2008) A Study on the Relationship between the Geomorphology and Vegetation Distribution of the Coastal Dunes in the Western Chianshuiwan, Sanjhih of Taipei County. Journal of Geographical, 51, 1-20.

[6] Lee, L.-H. (2013) Carbon Cycling on Intertidal Mudflats of the Kaomei Wetland. PH.D. Thesis, Department of Life Sciences, Chung Hsing University, Taichung, 97 p.

[7] Pen, C.-W. (2015) Phytoplankton Productivity and Trophic Models of Yunlin Coastal Water. Master's Thesis, Department of Life Sciences, Chung Hsing University, Taichung, $97 \mathrm{p}$.

[8] Xi, J.-G., Yang, Z.-H., Guo, S.-J., Wang, Q.-G., Zhang, J.-H. and Wang, D.-Z. (2015) The Correlation between Soil Physical and Chemical Properties and Soil Microbes in Different Types of Nitraria Dune. Acta Prataculturae Siniva, 23, 64-74.

[9] Liu, Z.-Y., Dong, Z.-B., Zhao, J., Li, L.-L. and Xiao, W.-Q. (2020) Effects of Artificial Sand Fixation on Sediment Characteristics and Soil Nutrients. Acta Ecologica Sinica, 40, 1383-1491. https://doi.org/10.5846/stxb201812212780

[10] Chen, Y.-X., Ding, G.-D., Gao, G.-L., Zhang, Y., Zhao, Y. and Wang, L. (2019) Content Characteristics of Organic Matter and Calcium Carbonate of Aeolian Soils in Hulun Buir Sandy Land. Soil and Water Conservation in China, 17, 104-1110. http://doi.org/10.16843/j.sswc.2019.04.013

[11] Ueng, Y.-T., Wang, Y.-K., Tsao, C.-W., Tung, S.-C., Hsu, J.-T. and Chang, Y. (2020) Monitoring and Assessment of Oyster and Barnacle Larvae Settlement in an Oyster Farm in Western Taiwan. Natural Resources, 11, 112-126.

[12] Google Company (2020). https://www.google.com.tw/maps/place/ 
[13] Krebs, C.J. (1999). Ecological Methodology. 2nd Ed., Benjamin/Cummings, 620 p., Menlo Park, CA.

[14] Hsieh, C.-H. (2012). An Institution Analysis on the Environmental Impacts at Coastal Area Associated with Petrochemical Industry. Master's Thesis, Institute of Ocean Affairs, Sun Yat-sen University, Guangzhou, $111 \mathrm{p}$.

[15] Chen, H.-C., Lin, M.-N. and Guo, S.-F. (2006). The Impact of Muddy Mud on Ecology and Oysters. Agricultural Knowledge Base.

https://kmweb.coa.gov.tw/knowledgebase.php?id=8308

[16] Teng, Y.-L., Su, J.-C., Chen, Y.-C. and Kung. C.-S. (1995) Numerical Simulation about Advection and Dispersion of Suspended Material Due to Offshore sand Dredging and the Related Oceanic Ecological Impact Assessment. The 17 th Ocean Engineering Seminar and 1995 Cross-Strait Port and Coastal Development Seminar, Taiwan, 9-10 November 1995, 1585-1598.

http://www.tsoe.org.tw/downloads/thesis/1995F9.pdf 